\title{
Do CÂNONE MODERNISTA À NOÇÃo ANTROPOLÓGICA DE CULTURA: $O$ CONCEITO DE CULTURA NAS POLÍTICAS CULTURAIS DO GOVERNO LULA (2003-2011)
}

\author{
Marcela Silva de SANTANA* \\ Maria Eduarda da Mota ROCHA**
}

\begin{abstract}
RESUMO: Este artigo analisa a concepção de cultura predominante nas políticas culturais do Governo Lula, à luz de transformações mais gerais do campo cultural brasileiro, notadamente aquelas trazidas pela consolidação de uma indústria cultural nas décadas de 1960-70 e pelo enfraquecimento do cânone modernista como critério exclusivo de avaliação das obras e manifestações culturais. Assim, apresentaremos as linhas gerais das políticas culturais do governo Lula, apontaremos os momentos principais da institucionalização e consagração do cânone modernista no Brasil e refletiremos sobre o significado e os impasses da adoção de um conceito antropológico de cultura no período lulista. $\mathrm{O}$ artigo debateu como as mudanças nas políticas culturais apareceram relacionadas ao enfraquecimento de uma visão mais especializada da cultura como produção artística e intelectual de vanguarda, em direção ao fortalecimento de uma noção de cultura como modo de vida, expandindo a gama de atividades legitimadas pelo Estado em políticas cultuais mais diversas e inclusivas.
\end{abstract}

PALAVRAS-CHAVE: Políticas culturais. Governo Lula. Conceito de cultura. Modernismo.

\footnotetext{
* UFPE - Universidade Federal de Pernambuco. Campus Recife. Programa de Pós-Graduação em Sociologia. Recife - PE, Brasil. 50670-901. marcelassantana@gmail.com. https://orcid.org/0000-00018309-9007.

** UFPE - Universidade Federal de Pernambuco. Campus Recife. Programa de Pós-Graduação em Sociologia. Recife - PE, Brasil. 50670-901. me.rocha@uol.com.br. http://orcid.org/0000-0002-36836614.
} 


\section{A redefinição das políticas culturais estatais no governo Lula}

A gestão do Ministério da Cultura (MinC) no governo Lula se iniciou em 2003, e logo na ocasião de sua posse, o então ministro Gilberto Gil deixou claro um dos pontos essenciais da política: a defesa por uma mudança na compreensão da cultura no âmbito das políticas culturais, quando ela passaria a significar não somente as artes eruditas ou o patrimônio em seu sentido comum, mas toda a produção de significados, valores e hábitos de uma sociedade (GIL, 2003). Tivemos, então, a adoção de uma concepção mais antropológica da cultura como um modo de vida (WILLIAMS, 1992), em detrimento de uma concepção mais modernista e folclorista da cultura que havia predominado em políticas culturais brasileiras em décadas anteriores. Este artigo pretende discutir este fato à luz de transformações mais gerais do campo cultural brasileiro, notadamente aquelas trazidas pela consolidação de uma indústria cultural nas décadas de 1960 e 1970 e pelo enfraquecimento do cânone modernista como critério exclusivo de avaliação das obras e manifestações culturais. Com este intuito, apresentaremos as linhas gerais das políticas culturais do governo Lula, apontaremos os momentos principais da institucionalização e consagração do cânone modernista no Brasil e refletiremos sobre o significado e os impasses da adoção de um conceito antropológico de cultura em um contexto até então marcado por aquele cânone.

Durante o governo Lula, uma reforma institucional no interior do MinC resultou na criação de novos departamentos e secretarias, como a Secretaria da Identidade e da Diversidade Cultural; e fortalecidos outras instituições, como a Fundação Nacional de Artes (FUNARTE). Um dos focos da atuação desta gestão esteve na tentativa de um investimento em políticas de Estado construídas a partir de uma articulação com entes federados e sociedade civil. Isto se deu principalmente a partir de três frentes: a implantação do Sistema Nacional de Cultura (SNC) e do Plano Nacional de Cultura (PNC) e a aprovação do Projeto de Emenda Constitucional (PEC) 150 (RUBIM, 2010). Uma das principais mudanças empreendidas ao longo dos sete anos de governo foi a construção de uma política cultural com maior participação da sociedade civil, através de um conjunto de seminários, conferências e encontros, que pudessem garantir uma maior participação não só dos criadores, mas também dos consumidores da cultura. A construção do PNC, por exemplo, envolveu os poderes Executivo e Legislativo, além de discussões públicas através da internet e das conferências e seminários realizados nos estados brasileiros. No início de 2009, os documentos produzidos nestas discussões foram recolhidos e analisados no âmbito do ministério, para subsidiar a produção final do PNC (MINISTÉRIO DA CULTURA, 
2008). A partir de ações como estas, o Estado tentou criar uma agenda de políticas públicas para a cultura que sobrevivesse à instabilidade de governos, que não fosse regida exclusivamente pelos atores situados no mercado, mas também que se afastasse das heranças autoritárias de políticas culturais no país (RUBIM, 2010). ${ }^{1}$

Distanciando-se de uma tradição de política pública de cultura no Brasil que usualmente valorizava sobretudo o patrimônio e as artes eruditas, o MinC aumentou seu raio de atuação incluindo, por exemplo, pela primeira vez, as culturas indígenas entre as suas preocupações (RUBIM, 2010). Nesse contexto, um dos programas que necessariamente passou por essa ampliação da ideia de cultura e que ganhou visibilidade e investimentos no interior do MinC, foi o Programa Cultura Viva, em especial pela atuação no projeto dos Pontos de Cultura. Criado em 2004, o projeto tem como proposta principal reconhecer saberes locais, potencializar e apoiar institucional e financeiramente a produção cultural já existente em diversos lugares do Brasil (2019). Através de seleção a partir de edital público, o MinC seleciona essas instituições e firma um convênio com estas, que passam a receber $\mathrm{R} \$ 185 \mathrm{mil}$ em cinco parcelas semestrais, sendo $\mathrm{R} \$ 20$ mil destinados a aquisição de aparelhagem eletrônica e os demais para qualquer atividade que o Ponto de Cultura desejar desenvolver, dependendo das suas condições e criatividade particulares. A criação do programa possibilitou um reconhecimento das produções culturais espalhadas em diversos cantos do país, principalmente aquelas ligadas às comunidades tradicionais: "Comumente excluídos das políticas públicas, com o Ponto de Cultura as expressões tradicionais se afirmam como sujeitos diferenciados na forma de fazer política" (TURINO, 2009, p.76).

Sendo assim, este alargamento conceitual vai significar também, e principalmente, uma transformação nas estratégias políticas do Estado na área da cultura. Essa ampliação, anunciada na posse, vai sendo consolidada como diretriz das políticas nacionais, sendo, inclusive, elencada como referencial conceitual no Plano Nacional de Cultura. É preciso, então, analisar o significado desta mudança na concepção de cultura no governo Lula para o campo cultural como um todo, no qual ela reforça o declínio do cânone modernista de cultura, sobretudo no que diz respeito à leitura nacionalista que se fazia deste.

\footnotetext{
${ }^{1} \mathrm{~A}$ instabilidade apontada por Rubim pode ser percebida no contexto mais recente, por exemplo, pela total extinção do Ministério da Cultura pelo então Presidente Jair Bolsonaro através da MP 810/19, o qual tornou a pasta da Cultura uma Secretaria parte do Ministério da Cidadania, e meses depois, parte do Ministério do Turismo.
} 


\section{A institucionalização de um cânone modernista de cultura no Brasil}

Não cabe aqui descrever o lento e duradouro processo de institucionalização de um cânone modernista de cultura no Brasil, mas podemos destacar alguns marcos importantes. O primeiro, sem dúvida, é a Semana de Arte Moderna realizada em 1922 na cidade de São Paulo, que trouxe a um novo patamar a dinâmica entre localismo e cosmopolitismo que, segundo Antonio Candido (1965) caracteriza a vida cultural brasileira. Na primeira geração de modernistas, o primitivismo, que na Europa significava a fuga do familiar ao exótico, é ressignificado como a busca pelas raízes de uma cultura nacional em formação. Deste modo, as linguagens das vanguardas europeias mais cosmopolitas eram postas a serviço do projeto de construção nacional, que passava a ser, juntamente com o primado da inovação formal, um traço forte do modernismo brasileiro que se prolongou nas gerações seguintes, apesar das divergências tanto no interior de cada geração quanto entre elas. $\mathrm{O}$ foco na identidade nacional tornou-se o eixo da conversão do modernismo em projeto ideológico nos anos 1930, para além da sua dimensão propriamente estética. Isso ficou particularmente visível na atuação de Mário de Andrade no Departamento de Cultura de São Paulo, e na crescente preocupação de registro das culturas populares com vistas a esta pesquisa das raízes da cultura brasileira (LAFETÁ e CANDIDO, 2000).

Neste contexto, ocorreu uma primeira ampliação da ideia de cultura no âmbito das políticas culturais em nível federal, que passava a incluir, além das artes eruditas, também o patrimônio, as produções intelectuais e a cultura popular. Em colaboração com o ministro Gustavo Capanema, no anteprojeto para criação do Serviço do Patrimônio Histórico e Artístico Nacional (SPHAN), Mário de Andrade sistematizou uma primeira noção ampliada de cultura no interior das políticas culturais, naquele momento, a partir do conceito de arte: "Arte é uma palavra geral, que neste seu sentido geral significa a habilidade com que o engenho humano utiliza-se das ciências, das coisas, dos fatos" (BOTELHO, 2007, p.56). Porém, como lembra Sérgio Miceli (2001), o anteprojeto foi abandonado, pois a extrema generosidade etnográfica de Mário de Andrade ia de encontro às circunstâncias de unidade do momento político, que demandava a construção de uma visão monolítica da identidade nacional, e a política do SPHAN acabou por se reduzir à preservação de monumentos vinculados a uma história da cultura da classe dirigente brasileira (MICELI, 2001).

Apesar do caráter restrito da atuação do SPHAN, a busca de uma identidade brasileira compelia os intelectuais e artistas, desde o modernismo, a se debruçarem sobre as culturas populares no intuito de encontra os símbolos e as formas desta 
nacionalidade. Nesse contexto, símbolos como o samba, foram sendo manipulados e transformados em elementos típicos não de uma parcela, mas da totalidade representada por esse ser nacional, esse povo miscigenado e cordial. Em um contexto de centralização e autoritarismo, o foco da política nacional de cultura no fim dos anos de 1930 estava no estabelecimento de um projeto nacional que superasse os conflitos políticos através da afirmação de uma imagem de uma identidade nacional que pudesse centralizar e reunir todas as parcelas da população brasileira em torno do regime estabelecido. Naquele momento a afirmação da unidade através da busca de uma possível identidade nacional, somado ao controle da produção cultural, aparecem como chave da política pública de cultura.

Ao tratar da vida cultural da cidade de São Paulo na década de 1950, Maria Arminda do Nascimento Arruda (2001) descreve o momento seguinte do modernismo brasileiro, quando este se enraíza, envereda para muitas linguagens além da literatura e ganha instituições e eventos que passam a dar suporte à sua difusão ampliada, como o Museu de Arte Moderna (MAM) e a Bienal de São Paulo. A autora recupera uma formulação de Antonio Candido para lembrar que o modernismo foi, em grande medida, uma matriz cultural que se projetou para o país a partir de São Paulo. Segundo Arruda (2001), apesar de, nos anos 1950, persistir a multiplicidade de linguagens e estilos que caracterizou o modernismo desde a década de 1920, é possível perceber as convergências no que diz respeito ao impulso de expressar a nova dinâmica urbana que passava a caracterizar São Paulo como metrópole. O primado da inovação formal e o tratamento das tensões entre o tradicional e o moderno marcaram diferentes expressões da vida cultural paulistana no período e, como tal, reatualizaram e institucionalizaram o cânone modernista da cultura em um grau sem precedentes, para além das rupturas explícitas com relação às primeiras gerações de modernistas, cujas linguagens passavam a ser vistas como rotinizadas. $\mathrm{O}$ elo de continuidade pode ser identificado na experimentação estética e na centralidade do problema da construção nacional, em ambas as gerações, apesar da sua diversidade interna. Tratando do período que se inicia em 1945, ano terminal do primeiro ciclo do modernismo, Arruda (2001, p.30) sintetiza: "Esse momento, dilacerado por posições divididas entre a vontade de representar o país, aglutinado em torno de certos projetos e do desejo de nos inserir, enfim, nos parâmetros universais, da cultura, caracterizou-se por visível fragmentação no âmbito interno às linguagens".

A diversidade que caracteriza a produção cultural modernista de meados do século, em meios aos debates sobre "realismo, figuração, abstracionismo, expressão social, nacional e internacional" (ARRUDA, 2001, p.18), não deve obscurecer o fato 
de que a cifra modernista vai adquirindo, até pelo menos as últimas décadas do século $\mathrm{XX}$, um valor que nenhuma outra possuía no campo cultural brasileiro.

\section{O modernismo, o nacional-popular e as políticas culturais do Estado brasileiro}

Quando as políticas culturais foram se institucionalizando no Brasil, a prática modernista de mobilizar a cultura para a formação da identidade nacional foi incorporada pela tradição do nacional-popular, se não do ponto de vista da inovação formal, pelo menos do ponto de vista da canalização de energias estéticas para o projeto de construção nacional para o qual a representação do povo é indispensável, seja para o Estado, os meios de comunicação de massa e até mesmo para as vanguardas estéticas esquerdistas. Segundo esta concepção modernista ressignificada nos termos do nacional-popular, o modo de incorporação das culturas populares era, por um lado, a sua conversão em matéria-prima para a composição de obras eruditas pelos artistas de vanguarda, e, por outro lado, o seu engessamento sob a forma estanque da tradição pelo folclorismo. Analisando a produção musical brasileira da primeira metade do século XX, Wisnik (1982, p.134) aponta uma aliança entre estes dois pólos da produção cultural na instituição de uma linha "sanitário-defensiva" que deveria demarcar claramente os limites entre a "ruim" e a "boa" música. O campo musical se dividia entre, de um lado, aquela aliança e, de outro, a música popular urbana comercial e a erudita europeizante. Estas duas últimas eram descartadas porque não passavam no teste de autenticidade quanto ao seu caráter nacional. Desde a era do Rádio, nos anos 1940, portanto, a afirmação de um cânone modernista de cultura veio de par com o surgimento de uma música comercial baseada nos meios de comunicação que não interessava ao projeto ideológico do nacional-popular, voltado a uma visão essencializante de povo, melhor representada pelo folclore.

A este respeito, é importante registrar que, na década de 1950, esta representação do povo sofreu uma inflexão entre os artistas e intelectuais de diferentes posições políticas e o conceito de cultura passou a ser associado também à transformação social. Essa chave de interpretação tomou corpo no âmbito do Instituto Superior de Estudos Brasileiros (ISEB), órgão formulador das principais doutrinas do governo de Juscelino Kubistchek (1956-1961). Ela influenciou de modo decisivo as gerações seguintes, em especial na atuação do Centro Popular de Cultura (CPC), de inspiração comunista. Segundo tal visão, seria através de uma cultura popular e nacional que ocorreria a tomada de consciência política do povo, sua desalienação. Mesmo após o golpe militar de 1964, quando tiveram fim as atividades destes grupos, 
uma gama de conceitos políticos e filosóficos forjados naquela época encontrou popularidade nos setores de esquerda (ORTIZ, 2006).

Existia, portanto, uma tensão entre passado e futuro na maneira como os produtores e gestores concebiam a cultura popular. Marcelo Ridenti (2005) identifica a raiz desta tensão no caráter romântico-revolucionário da estrutura de sentimentos que caracterizava artistas e intelectuais brasileiros até, pelo menos, a década de 1970. Presente em posições à esquerda e à direita do espectro político, esta estrutura de sentimentos dita a preocupação em buscar no povo a matéria-prima para uma construção nacional que pode ser concebida em termos conservadores ou progressistas. Naquele momento, entretanto, em nenhuma destas perspectivas, são respaldadas as produções que integram as linguagens e conteúdos populares à lógica do mercado. Neste sentido, popular refere-se ainda a uma visão tradicionalista de povo.

No âmbito do Estado, esse olhar para o povo em busca de imagens para a construção nacional dita o surgimento de instituições especializadas na atuação sobre a cultura desde a Era Vargas, mas ganha um impulso renovado depois do golpe militar de 1964. Renato Ortiz esclarece:

O Estado, assumindo o argumento da unidade da diversidade, torna-se brasileiro e nacional, ele ocupa uma posição de neutralidade, e sua função é simplesmente salvaguardar uma identidade que se encontra definida pela história. O Estado aparece, assim, como guardião da memória nacional e da mesma forma que defende o território nacional contra as possíveis invasões estrangeiras preserva a memória nacional contra a descaracterização das importações ou das distorções dos pensamentos autóctones desviantes. (ORTIZ, 2006, p.100).

Neste momento, o Estado começa a criar mecanismos para fazer da cultura o espaço de consolidação de sua hegemonia, que passava pela unificação de um mercado de bens simbólicos e pela integração nacional, tentando reunir todas as diferenças regionais, culturais e políticas, em torno deste projeto de desenvolvimento. Assim, a cultura é meio de integração sob constante controle.

O que já se pode observar naquela época é o desenvolvimento de duas tendências complementares do Estado em relação à cultura: ele interfere proibindo e censurando aquilo que é visto como prejudicial à imagem "séria" do Brasil, mas, em contrapartida, atua promovendo a imagem sui generis de nossa cultura. (OLIVEN, 1984, p.50). 
Em sua análise da política cultural no Brasil nos anos 1970, Gabriel Cohn (1984) coloca que a ênfase na garantia de uma personalidade nacional aparecia enquanto parte de uma política que, investia maciçamente na área cultural através da criação de organismos de gestão e através do financiamento e apoio direto à produção. Paralelamente a esta atuação, o Estado criava instrumentos de controle sobre o campo cultural, tentando neutralizar as produções contrárias ao regime. A valorização de uma suposta identidade nacional passava pela ênfase na espontaneidade do processo cultural e da sua fonte: o povo. Esta estratégia, nesse sentido, tinha por objetivo diminuir o poder das elites intelectuais e artísticas no interior do campo cultural, devido ao esquerdismo predominante entre estes setores da sociedade naquele momento. Como veremos, o contexto de reaparecimento do antielitismo nas políticas culturais do governo Lula é muito diferente, uma vez que amplia de fato o espectro de manifestações consideradas dignas de financiamento público, apesar dos impasses gerados por esta ampliação.

Completando a dinâmica do campo cultural brasileiro no período da Ditadura Militar (1964-1985), estava uma indústria cultural formada sob fortes incentivos institucionais, técnicos e publicitários por parte do Estado. Neste momento, entre as décadas de 1960 e 1970, o nacional-popular penetrou os meios de comunicação e alcançou seu auge nos diferentes setores da produção cultural, especialmente a música, o cinema e a televisão, mas simultaneamente, deparou-se com os processos que viriam solapar a sua hegemonia no campo cultural brasileiro. Por um lado, o ponto alto do nacional-popular se deu com a ampliação do mercado cultural através do qual ele se disseminou muito além dos círculos estatais ou vanguardistas onde havia surgido. Por outro lado, este mesmo mercado cultural que se ampliou e se integrou nacionalmente através da TV e de outras grandes empresas que passaram a produzir e difundir bens culturais alterou a maneira como a identidade nacional era costumeiramente representada, nos termos de uma visão tradicionalista de povo. Temos, então, uma diluição e uma reformulação do nacional-popular no interior de formatos industriais de cultura, como a telenovela e a publicidade.

\section{O declínio do cânone modernista de cultura no Brasil e as políticas culturais estatais}

A formação de uma indústria cultural redefine o próprio conceito de popular no Brasil, afastando-o lentamente da visão essencializante do nacional-popular para aproximá-lo dos padrões de uma sociedade definitivamente urbanizada e 
industrializada, na qual a produção de cultura também segue uma lógica majoritariamente industrial (ORTIZ, 1988). Marcelo Ridenti (2000) lembra que, nos anos de 1960 e 1970, as telenovelas da Globo podiam ser vistas como a manifestação mais importante da tradição nacional-popular gestada nas décadas anteriores, agora convertida em ideologia que justificava os rumos tomados pela sociedade brasileira com o Golpe de 1964 e o poder da própria Globo nesta sociedade. A incorporação de artistas e intelectuais ligados àquela tradição pela indústria cultural a partir do golpe militar de 1964 foi visível, especialmente na publicidade (ROCHA, 2010) e na TV (RIDENTI, 2000). Na nova situação, popular era, sobretudo, a produção cultural a qual milhões de brasileiros estavam expostos através dos mecanismos do mercado, inviabilizando a manutenção da linha sanitário-defensiva que deixava de fora a produção comercial quando se tratava de incorporar o povo na construção da identidade nacional.

A redefinição do campo cultural brasileiro neste contexto e os sinais de crítica ao cânone modernista identificado ao nacional-popular ficaram evidentes no Tropicalismo, movimento cultural do final dos anos 1960 e começo dos anos 1970 de que fez parte o ministro da cultura do governo Lula, o cantor Gilberto Gil. Os tropicalistas reeditaram o conceito de antropofagia, caro aos primeiros modernistas, que pode ser definido como a visão segundo a qual a característica fundante da cultura brasileira é a sua capacidade de digerir as diversas matrizes culturais que participaram da formação do Brasil. No novo cenário, ele passa a significar também a possibilidade de incorporar linguagens e conteúdos provenientes de diferentes ramos da indústria cultural. Assim, ainda que continuassem focados no problema da construção nacional, os tropicalistas encontram respostas que assimilam estéticas estrangeiras, a partir de então definitivamente mediadas pelo mercado (RIDENTI, 2000). Neste sentido, se contrapunham diretamente ao engessamento da identidade brasileira segundo a concepção nacional popular, e o exemplo mais evidente é a polêmica gerada pelo uso tropicalista da guitarra elétrica na música brasileira. Temos, então, um declínio da ênfase no nacional em favor de um cosmopolitismo que entra por um mercado ampliado em que ecoam também produtos e formatos estrangeiros, já sob a rubrica da cultura pop.

No novo cenário, o mercado assume definitivamente o protagonismo no campo cultural brasileiro, de maneira que, estimulado pelas doutrinas neoliberais que aportam no país no final da década de 1980, o próprio Estado foi adotando políticas culturais que transferiram para as empresas as decisões sobre os principais investimentos na cultura. Tais políticas ficaram marcadas pela criação e estabelecimento das leis de incentivo como as principais fontes de financiamento para 
projetos culturais no Brasil. Esse processo se inaugurou em 1986, com a Lei Sarney (Lei $\mathrm{n}^{\circ} 7.505$, de 02 de junho de 1986), que foi uma tentativa de aumentar o volume de verbas para custeamento das produções culturais. Segundo este modelo, o Estado concederia abatimento nos impostos devidos de empresas que investissem na cultura, delegando para a iniciativa privada a responsabilidade da escolha das atividades que seriam patrocinadas por recursos, que, no final das contas, eram públicos. Em 1991 foi criada a Lei Rouanet, só regulamentada em 1995, que segue o mesmo modelo. Na gestão cultural, as leis de incentivo e a valorização do marketing cultural se apresentam como os principais instrumentos utilizados no governo do presidente Fernando Henrique Cardoso (FHC). Seu Ministro da Cultura, Francisco Weffort (1991), publicou uma brochura em que deixa clara a compreensão então vigente acerca da relação entre Estado e mercado no campo cultural, intitulada Cultura é um bom negócio.

No modelo subjacente às leis de incentivo da década de 1990 há uma distribuição desigual dos recursos por região, que se concentram no sul e sudeste do país. Além disso, ele gera uma concorrência desequilibrada entre os produtores culturais de grande, pequeno e médio porte, que lutam pela captação dos mesmos recursos, tendo que dominar uma lógica administrativa que difere muito da lógica da criação artística (BOTELHO, 2001). Nesse sentido, a figura dos intermediários culturais é fortalecida - aqui referida àqueles profissionais capacitados para lidar com trâmites burocráticos e com formação na área de marketing - criando, assim, um mercado que se volta para a criação de imagens institucionais das empresas e não para produção de bens culturais como um fim em si mesmo. As políticas culturais baseadas exclusivamente em tais mecanismos trazem como consequência a desvalorização e real inanição de diversas áreas que não produzem lucro ou não tem efeito de marketing para as empresas. Assim, no governo FHC, foi completamente transferida para o mercado a responsabilidade de decidir para onde ia o dinheiro público. Dessa forma, o Estado, que deveria promover a diversidade cultural, um valor apontado pela Organização das Nações Unidas para a Educação, a Ciência e a Cultura (UNESCO), acabou por favorecer as produções que já encontram sombra no seio da própria indústria cultural, mais afeitas a gerar uma boa imagem para as corporações (RUBIM, 2010).

Em contraste com a gestão de FHC, o governo Lula empreendeu um esforço de fortalecimento do poder do Estado diante do mercado. As suas políticas culturais marcam a culminância de um processo lento e de longa duração que nos trouxe até a situação em que passa a prevalecer uma concepção antropológica de cultura em detrimento de uma concepção da cultura como belas artes, associada ao modernismo. 
Desde o seu discurso de posse, em 2003, o titular do MinC, Gilberto Gil deixou clara a nova concepção que deveria nortear a atuação do Estado: cultura deveria contemplar a produção constante de significados, hábitos, valores e identidades que surgem a partir das interações sociais (GIL, 2003). Tal concepção acabou reverberando no Plano Nacional de Cultura, que diz:

A Cultura não se resume tão-somente ao campo das belas-artes, da filosofia e da erudição, nem tampouco ao mundo dos eventos e efemérides. A Cultura deve ser considerada como o conjunto dos traços distintivos que caracterizam um determinado grupo social. Além das artes, da literatura, contempla, também, os modos de vida, os direitos fundamentais do homem, os sistemas de valores e símbolos, as tradições, as crenças e o imaginário popular. (MINISTÉRIO DA CULTURA, 2009, p.5).

Tal concepção antropológica de cultura apareceu no cenário mundial associada à ideia de diversidade apregoada pela UNESCO. Na verdade, desde meados do século XX, autores ligados aos estudos culturais britânicos defendiam a necessidade de conceber a cultura como um modo de vida ou um sistema significante que se expressa tanto nas produções eruditas quanto nos produtos dos meios de comunicação, na moda, no design, etc. Neste sentido, Raymond Williams (1958) nos ensina que a cultura é ordinária. Mas a UNESCO foi a principal catalisadora dos debates acerca do alargamento do conceito de cultura e seu direcionamento para as políticas culturais. Ela conferiu à área cultural uma maior densidade institucional, a partir de uma série de convenções, declarações e outros instrumentos jurídicos. No âmbito desta instituição, tomou corpo um grande apelo a novas políticas públicas de cultura que pudessem promover a identidade e a diversidade cultural, frente à padronização decorrente dos avanços das indústrias culturais e da globalização. $\mathrm{Na}$ década de 1970, com uma série de conferências em diversos países que culminaram na Conferência Mundial Sobre as Políticas Culturais (MUNDIACULT) em 1982, passou a surgir no âmbito UNESCO uma dilatação do conceito de cultura através da sua associação aos conceitos de desenvolvimento e diversidade (ALVES, 2011). Esse processo teve seu auge com a aprovação, em 2001, do texto da Declaração Universal Sobre a Diversidade; e depois com a aprovação da Convenção Sobre a Proteção e a Promoção da Diversidade das Expressões Culturais, em 2005. Segundo Alves (2011) o governo brasileiro apareceu como protagonista no processo de aprovação da convenção a partir de dois interesses: primeiro, a necessidade de incorporar à estrutura da administração cultural o valor da diversidade cultural, inserindo-o em políticas 
culturais voltadas para as culturas populares; e, segundo, a liderança na formação de um novo discurso que passa pela consolidação de novas categorias como indústrias da criatividade, diversidade cultural, patrimônio imaterial, etc.

Nesse sentido, a ampliação do conceito de cultura que aparece no discurso do MinC no governo Lula tem como principal âncora o valor da diversidade cultural. Como dito anteriormente, o alargamento do conceito de cultura no interior das políticas culturais no Brasil, já começa a aparecer na primeira metade do século XX, quando surgia imbricado com a conformação de uma identidade nacional que contemplava as culturas populares, desde que moldadas às exigências daquela identidade. Segundo Alexandre Barbalho (2007, p.56), na política cultural do governo Lula, a concepção de identidade enquanto conjunto monolítico e único é ressignificada de modo a assimilar também a ideia de pluralidade. No Plano Nacional de Cultura em 2009, a questão da diversidade aparece em destaque enquanto um dos desafios à política cultural no país, e, segundo o documento, a adoção de um novo referencial conceitual acerca da compreensão da cultura aparece como essencial para responder a esses desafios.

A DIVERSIDADE ÉTNICO-CULTURAL É NOSSA GRANDE RIQUEZA: Que política cultural queremos para um País marcado por forte diversidade cultural, fruto de nossa formação histórico-social? Entendida a diversidade cultural como a construção social e histórica das diferenças, como fazer para que as diferentes formas do fazer cultural dos variados grupos étnico-culturais estejam presentes no Plano Nacional de Cultura? Como fazer para que a construção de uma política pública de cultura não tome a identidade nacional como um conjunto monolítico e único, mas que reconheça e valorize as nossas diferenças culturais, "como fator para a coexistência harmoniosa das várias formas possíveis de brasilidade"? (MINISTÉRIO DA CULTURA, 2009, p.4).

Assim, pode-se perceber que por mais que a política cultural se proponha a compreender e valorizar as diferenças - através da ampliação do fomento, dos Pontos de Cultura, de uma melhor distribuição de recursos em termos regionais, entre outros a concepção de cultura brasileira como síntese das diferenças ainda se faz presente, e a ideia de unidade nacional é difícil de ser descartada. Ela é reposta na chave da diversidade cultural, tida, então, como grande característica daquilo que nos faz brasileiros. Mas, para além desta continuidade, a ideia de diversidade introduz uma ruptura, uma vez que provoca o declínio de um conceito de cultura prioritariamente ligado às artes eruditas: 
Com frequiência, a política cultural é pensada com ênfase exclusiva nas artes consolidadas. Considerando-se que a diversidade cultural é o maior patrimônio da população brasileira, no âmbito do PNC busca-se transcender as linguagens artísticas, sem contudo, minimizar sua importância. (MINISTÉRIO DA CULTURA, 2008, p.11).

Um conceito ampliado de cultura aparece nos textos oficiais ligado a três dimensões: simbólica, cidadã e econômica. A primeira dimensão diria respeito à cultura enquanto infinitas possibilidades de produção simbólica, a partir de crenças, valores, identidades etc.; é aqui que a ideia de diversidade cultural aparece enquanto essencial na conformação de um conceito ampliado de cultura. A segunda dimensão diz respeito à cultura enquanto direito humano fundamental, como garantido pela Constituição Brasileira de 1988. Nesse sentido, o alargamento no conceito de cultura está ligado a uma compreensão deste direito e enquanto obrigação constitucional do Estado e condição fundamental para o exercício da cidadania. Logo, a política cultural obrigatoriamente deve ter isto como base legal e pressuposto essencial, o que se estabelece enfatizando a necessidade de garantir o acesso dos brasileiros aos bens simbólicos. A terceira dimensão diz respeito à cultura enquanto parte importante de um cenário de desenvolvimento do país, "inserida em um contexto de valorização da diversidade, a cultura também deve ser vista e aproveitada como fonte de oportunidades de geração de ocupações produtivas e de renda e, como tal, protegida e promovida pelos meios ao alcance do Estado". (MINISTÉRIO DA CULTURA, 2008, p.11). Estamos muito próximos daquela tendência verificada por Yúdice (2004) de conceder à cultura um papel adicional de recurso para o desenvolvimento e a cidadania, retirando-lhe da órbita de influência mais direta da ideia de nacionalidade. Diz ele, "uma vez que todos os atores da esfera cultural se prenderam a essa estratégia, a cultura não é mais experimentada, valorizada e compreendida como transcendental" (YUDICE, 2004, p.28).

\section{A concepção ampliada de cultura e os impasses das políticas culturais do governo Lula}

Em todas as três dimensões do conceito de cultura enfatizado pelo governo Lula - simbólica, cidadã e econômica - temos uma dessacralização que o dissocia das belas artes para redefini-lo como parte dos modos de vida do povo brasileiro. Isto trouxe alguns impasses para as políticas culturais do período. Por um lado, a definição 
da cultura como modos de vida torna muito difícil a delimitação das fronteiras entre as produções culturais que devem e as que não devem receber apoio do governo. Se tudo é cultura, o que deve ser objeto de uma política cultural estatal? Por outro lado, considerando que a presença da indústria cultural na vida brasileira é incontornável, como estabelecer um limite entre a produção cultural de que o próprio mercado deverá se encarregar e aquelas que, por não se sustentarem segunda a lógica mercantil, não podem sobreviver sem o apoio do Estado? A resposta para ambos os impasses, como não poderia deixar de ser, tem sido política. Tais limites não se definem a priori, mas a partir das disputas entre os diferentes agentes que interpelam o Estado em busca de reconhecimento e recursos. Para concluir, vamos aludir a alguns casos que ilustram os impasses gerados pela concepção antropológica de cultura nas políticas culturais do governo Lula.

Podemos começar lembrando que o reconhecimento da legitimidade dos modos de vida como experiência cultural remete, não apenas à velha celebração da cultura popular, presente nas políticas de governos anteriores, mas também a práticas culturais que, apesar de não serem sustentadas pelo mercado, guardam afinidade com formatos e linguagens da indústria cultural. A criação de uma Secretaria do Audiovisual, por exemplo, é indicativa deste fato. Não se trata de uma secretaria do cinema, mas do audiovisual, muito próxima à produção da periferia carioca, a partir da experiência do Festival Visões Periféricas. Além disso, mesmo as manifestações populares mais tradicionais estão sob influência da lógica do espetáculo que parece ter extravasado a mídia e alcançado outras formas de produção cultural. A incorporação daquelas manifestações pela indústria do turismo e nas grandes festas financiadas pelo Estado não está isenta daquela lógica, como é possível perceber nas festas de São João das cidades nordestinas, no Carnaval de Recife, Rio de Janeiro e Salvador, na festa do Boi de Parintins, na região amazônica.

Apesar de se contrapor ao mercado como mecanismo exclusivo de sustentação da cultura, a recuperação do poder do Estado nesta esfera se dá em um contexto no qual a presença da indústria cultural é decisiva e pode aparecer para os gestores como um obstáculo à experimentação de formas que não ecoem os gostos predominantes. Lembremos, de passagem, que a ubiquidade da lógica de produção mercantil na cultura caracteriza, para Fredric Jameson (1996), o pós-modernismo, em contraste com o momento em que os enclaves modernistas funcionavam como espaços relativamente autônomos de produção da arte erudita que ocupava o topo da escala de consagração cultural. A predominância da lógica mercantil provoca uma série de dificuldades para uma política cultural que pretenda resistir àquela lógica. A este respeito, um dos maiores problemas elencados pelos ministros da cultura Gilberto Gil 
e Juca Ferreira foi o alinhamento entre uma ideia de cultura ampliada que parte da política de Estado e uma visão de cultura aliada aos interesses da iniciativa privada. É preciso considerar que o investimento obtido através da Lei Rouanet era o dobro do orçamento que o ministério dispunha para as políticas públicas, o que conformava uma dependência em relação aos recursos obtidos mediante renúncia fiscal, concentrando o poder decisório nos departamentos de marketing das grandes empresas. Os projetos submetidos à avaliação eram julgados por uma comissão autônoma ao ministério, o que para Gil e Ferreira era um obstáculo: "não tínhamos autonomia para determinar como a comissão deveria atuar e selecionar os projetos. Lidávamos com coisas deste tipo: a autonomia da comissão era garantida pela própria lei" (SILVA \& MIDLEJ, 2011, p.126). Assim, criava-se um hiato entre a defesa desta ideia ampliada de cultura e a política realizada através da Lei Rouanet. "As empresas estão ligadas a setores específicos da atividade produtiva que, por sua vez, tendem a estar mais ligados a determinados interesses culturais e estar mais concentrados em localidades que acabam se beneficiando fortemente dos investimentos". (GIL apud SILVA \& MIDLEJ, 2011, p.126).

Segundo o ex-ministro Gilberto Gil, em certa medida esta gestão avançou, visto que uma importante conquista para o alinhamento das políticas dos setores privados com as políticas públicas do ministério ocorreu a partir da presença do ministério nas estatais como a Petrobrás, Caixa Econômica do Brasil, Banco do Brasil e o Banco Nacional de Desenvolvimento Econômico e Social (BNDES), a partir da instalação de representações permanentes do MinC nesses órgãos (SILVA \& MIDLEJ, 2011). Estas estatais são grandes financiadoras de projetos culturais no Brasil. Para se ter uma ideia, o edital da Petrobrás, hoje, conta com recursos da ordem dos 80 milhões de reais por ano para a área cultural.

Apesar do esforço em submeter a lógica do mercado aos critérios da política cultural do governo, gestores culturais preocupados em ampliar o espaço para a produção e consumo de bens simbólicos alternativos em relação à indústria cultural têm que se haver com a sua força na disseminação de gostos e hábitos. Além disso, não podem ficar indiferentes à visibilidade midiática de artistas, seja na concessão de incentivos fiscais, seja na consagração propriamente cultural. Em junho de 2009, um embate entre o cantor Caetano Veloso e o Ministério da Cultura terminou com a autorização do uso da Lei Rouanet para financiar seu show. Em princípio, essa autorização havia sido recusada a pretexto de ser ele um artista comercialmente viável. O então ministro Juca Ferreira voltou atrás e lembrou que a Lei Rouanet não prevê esse tipo de restrição e que até outros cantores de maior público já haviam sido beneficiados (AITH, 2009). No tocante à consagração, em 2003, o presidente Lula e o 
ministro Gil concederam o prêmio da Ordem do Mérito Cultural a um grande número de artistas e intelectuais, chama a atenção à diversidade presente na lista que incluía desde Cândido Portinari (pintor modernista) e Pixinguinha (sambista tradicional), até os membros do Casseta e Planeta (humoristas de um programa da Rede Globo) (MINISTÉRIO DA CULTURA, 2003).

A força da lógica mercantil e da mídia no campo cultural brasileiro não se deve apenas ao fato de que são eles os principais instrumentos de acesso do grande público à cultura, mas também ao surgimento de uma geração de artistas e intelectuais para os quais os formatos e linguagens da indústria cultural são familiares desde a infância. Esta geração desconfiada em relação ao uso autoritário do nacional-popular nos anos 1970 e começo dos anos 1980 tende a abraçar um cosmopolitismo que se liga diretamente a matrizes culturais locais, sem passar pelo crivo da identidade nacional. Na música, por exemplo, a forte penetração de tendências europeias e americanas visível no Tropicalismo dos anos 1970 reverberou em outros movimentos culturais que, a partir dos anos 1980, passaram a contar até com uma imprensa especializada divulgando o punk, o hip-hop e vertentes da cultura pop. Em ambos os casos, a ideia de diversidade aparece como contraponto ao nacional-popular, traçando um contexto muito favorável à recepção das ideias propagadas pela UNESCO no mesmo período.

Enquanto as gerações modernistas de meados do século XX compreendiam a cultura como um instrumento de transformação social e de construção nacional, tomando para tanto, a cultura popular e o mundo rural como referências primeiras, via de regra, as novas gerações de produtores culturais têm nas linguagens e formatos da indústria cultural um parâmetro incontornável. A biografia muito particular de um desses produtores, o diretor de TV e de cinema Guel Arraes, pode ilustrar essa passagem. Ele dirige um núcleo no interior da Rede Globo que atua como um espaço de troca entre a emissora, carente de legitimidade diante da pressão da opinião pública e do aumento da concorrência, e uma geração de artistas vindos do vídeo independente, do jornalismo nanico (jornalismo independente de pequeno porte) e do teatro cômico dos anos 1980 (ROCHA, 2008). Se a estrutura de sentimentos é a partilha de crenças e sensibilidades que atuam como mediação entre a experiência histórica comum e a produção artística e intelectual, a dessa nova geração emerge da desconfiança em relação à apropriação autoritária do nacional-popular pelo Regime Militar, da recusa de uma compreensão estritamente classista da política, da influência de uma concepção mais psicanalítica e contracultural de liberdade. No caso dos artistas agrupados em torno de Guel Arraes, ela recupera dois elementos importantes do modernismo, pelo menos em suas pretensões: a busca pela inovação de linguagem e pela representação dos segmentos oprimidos da sociedade. Esses elementos, 
especialmente o primeiro, são a base para a reivindicação de uma legitimidade cultural que extrapola o âmbito da TV e, pelo menos no campo do cinema, se contrapõe explicitamente ao cânone cinema-novista (consagrado na década de 1960, na esteira da produção de Glauber Rocha).

A questão fundamental é saber até que ponto se trata de um veio que, por estar amparado na indústria cultural, alcança grande visibilidade, mas pouca consagração na esfera de produção erudita ou se, a partir dessa visibilidade, consegue ampliar os critérios de legitimidade cultural em todos os âmbitos. Ao contrário do que possa parecer, a resposta não é simples. No caso dos produtores que se agrupam em torno de Guel Arraes, um dos seus temas preferenciais, a periferia, acabou virando objeto de uma grande exposição realizada no Rio de Janeiro em 2005, e uma de suas idealizadoras, a pesquisadora Heloísa Buarque de Holanda (2005, n.p.), definiu-a como "uma exposição sobre a visualidade e a linguagem cultural da periferia do Rio de Janeiro, retratando sua maneira de captar o mundo da mídia e da moda de forma antropofágica, transformadora e criativa, dentro de sua realidade econômica". Indo além, ela afirma:

é inquestionável a importância dessas expressões culturais no conjunto da diversidade que nos caracteriza. Não podemos definir identidade cultural nacional, simplesmente porque ela não existe no singular. Nossa cultura é plural e as estéticas centrais e periféricas, como o tecnobrega de Belém, o funk carioca ou o hip hop paulistano, compõem essa multiplicidade, sendo cada vez mais reconhecidas, também por isso. (HOLLANDA, 2005, n.p.).

A referência à antropofagia e à identidade nacional, agora, no plural, indica que, mais do que a renúncia à antiga forma de consagração, temos aqui o aumento da disputa em torno do poder de definir os critérios de legitimidade cultural, e o fato de que a visibilidade midiática passa a contar como um recurso importante nessa disputa - como, de resto, tem contado nas disputas do campo político, religioso etc. Além disso, esse caso sugere também a projeção desta disputa no âmbito acadêmico, uma vez que a contestação ao cânone modernista empreendida por produtores culturais dentro e fora da indústria cultural recebe a chancela de pesquisadores como a própria Heloísa Buarque de Holanda e Hermano Vianna, interlocutor frequente de Guel Arraes e um claro defensor de uma releitura do valor cultural do funk carioca.

Vivemos, então, no Brasil, um momento de redefinição dos critérios de consagração cultural a partir das disputas entre atores situados nos diferentes ramos da produção erudita, nas vertentes mais tradicionalistas ou contemporâneas de cultura 
popular, nos filões mais afluentes ou limitados do mercado. Neste cenário, pelo menos durante o governo Lula, o Estado atuou em favor do enfraquecimento de uma concepção modernista de cultura como belas-artes e do fortalecimento de uma noção ampliada que contempla não apenas as produções mais tradicionais da cultura popular, mas aquelas que se utilizam de linguagens e influências mais contemporâneas. Sendo assim, a expansão do conceito de cultura a que se refere Gilberto Gil (2003) significa também uma transformação nas obrigações e estratégias possíveis do Estado na área da cultura. Para que uma política cultural abarque a dimensão antropológica, é necessária uma série de intervenções nas quais a amplitude deste conceito seja considerada, ou seja, toda a produção simbólica da sociedade. Nesse sentido, a redefinição da ideia de cultura anda ao lado de uma redefinição do papel do Estado e como este deve intervir na área cultural. A dilatação do conceito de cultura, ao mesmo tempo em que torna possível uma enorme mudança do ponto de vista da desigualdade na produção, distribuição e acesso aos bens culturais, é um grande desafio para qualquer política cultural, pois, abarcando a total produção simbólica dos seres humanos desenha um limite impossível para a intervenção. Segundo Isaura Botelho (2001, p.75), é necessário reconhecer os limites do campo de atuação em política pública, "uma política cultural que defina seu universo a partir do pressuposto de que 'cultura é tudo' não consegue traduzir a amplitude desse discurso em mecanismos eficazes que viabilizem sua prática”.

\section{FroM THE MODERIST CANON TO DE ANTHROPOLOGICAL CONCEPTION OF CULTURE: THE CONCEPT OF “CULTURE" IN THE CULTURAL POLICIES OF LULA ADMINISTRATION (2003-2011)}

ABSTRACT: This article analyses the conception of "culture" prevailing in the cultural policies of Lula Administration, in the light of more general transformations in the Brazilian cultural field, and specifically those brought forth by the consolidation of the cultural industry in the 1960s and 1970s decades and by the weakening of the modernist canon as exclusive criterion for the evaluation of works and cultural manifestation. Thus, the general lines of the cultural policy in Lula's government will be presented, the main moments of the institutionalization and consecration of the modernist canon in Brazil will be described, and a reflection will be given about the meaning and the deadlocks of the adoption of an anthropological concept of culture in Lula's period. The article discussed how changes in cultural policies were related to the weakening of a more specialized view of culture as avant-garde artistic and 
intellectual production, towards the strengthening of a notion of culture as a way of life (WILLIAMS, 1992), expanding the range of activities legitimized by the state in more diverse and inclusive cultural policies.

KEYWORDS: Cultural policies. Lula's administration. Conception of Culture. Modernism.

\section{DEL CANON MODERNISTA A LA NOCIÓN ANTROPOLÓGICA DE CULTURA: EL CONCEPTO DE CULTURA EN LAS POLITICAS CULTURALES DEL GOBIERNO DE LULA (2003-2011)}

RESUMEN: Este artículo analiza la concepción de "cultura" predominante en las políticas culturales del gobierno de Lula, basado en las transformaciones más generales del campo cultural brasileño, en particular las provocadas por la consolidación de una industria cultural en los años 1960-70 y por el debilitamiento del canon modernista como criterio exclusivo para la evaluación de obras y eventos culturales. Por lo tanto, presentaremos las líneas generales de las políticas culturales de la administración de Lula, destacaremos los principales momentos de la institucionalización y consagración del canon modernista en Brasil y reflexionaremos sobre el significado y los impases de adoptar un concepto antropológico de cultura en el período lulista. El artículo discutió cómo aparecieron los cambios en las políticas culturales relacionadas con el debilitamiento de una visión más especializada de la cultura como producción artística e intelectual de vanguardia, hacia el fortalecimiento de una noción de cultura como una forma de vida (WILLIAMS, 1992), ampliando el conjunto de actividades legitimadas por el estado en políticas culturales más diversas e inclusivas.

PALABRAS CLAVE: Políticas culturales. Gobierno de Lula. Concepto de cultura. Modernismo.

\section{Referências}

AITH, Márcio. MinC autoriza Caetano a usar benefícios fiscais. Folha Ilustrada, São Paulo, dia 23 jun. 2009. Disponível em:

https://www1.folha.uol.com.br/fsp/ilustrad/fq2306200909.htm Acesso em: 02 jun. 2011. 
ALVES, Elder P. Maia. A Economia Simbólica da Cultura Popular Sertanejonordestina. Alagoas: EDUFAL, 2011

ARRUDA, Maria Arminda do Nascimento. Metrópole e Cultura. São Paulo no meio século XX. Bauru-SP: Edusc, 2001.

BARBALHO, Alexandre. Políticas Culturais No Brasil: identidade e diversidade sem diferença. III Encontro de Estudos Multidisciplinares em Cultura, UFBA. Bahia, 2007.

BOTELHO, Isaura. Dimensões da cultura e políticas públicas. São Paulo em Perspectiva. São Paulo, 15(2), p.73-83, 2001.

A política cultural e o plano das idéias In RUBIM, Antonio

Albino C.; BARBALHO, Alexandre (orgs.). Políticas culturais no brasil. Salvador: EDUFBA, 2007.BRASIL. Secretaria Especial da Cultura. Disponível em: http://cultura.gov.br/?s=pontos+de+cultura. Acesso em: 26 nov. 2019.

CANDIDO, Antonio. Literatura e sociedade: estudos de teoria e história literária. São Paulo: Nacional, 1965.

COHN, Gabriel. A concepção oficial da política cultural nos anos 70 In: MICELI, Sergio (org.) Estado e Cultura no Brasil. São Paulo: Difel, 1984.

GIL, Gilberto. Discurso do ministro Gilberto Gil na solenidade de transmissão do cargo. Brasília, 2 jan. 2003. Disponível em: http://www.cultura.gov.br/site/categoria/odia-a-dia-da-cultura/discursos/. Acesso em: 19 abr. 2012.

HOLLANDA, Heloísa Buarque de. Entrevista: Estética da periferia. Catálogo da Exposição Estética da Periferia. Rio de Janeiro, 2005. Disponível em: http://www.heloisabuarquedeholanda.com.br. Acesso em: 02 jun. 2011.

JAMESON, Fredric. Pós-modernismo - a lógica cultural do capitalismo tardio. São Paulo: Ática, 1996.

LAFETÁ, João Luiz, CANDIDO, Antonio. 1930: A crítica e o modernismo. São Paulo: Editora 34, 2000.

MICELI, Sérgio. Intelectuais à brasileira. São Paulo: Companhia das Letras, 2001.

MINISTÉRIO DA CULTURA. Entrega da Ordem do Mérito Cultural de 2003. Brasília, 19 dez. 2003. Disponível em: http://www.cultura.gov.br/ Acesso em: 02 jun.

MINISTÉRIO DA CULTURA. Plano Nacional De Cultura - Diretrizes Gerais. Brasília, 2008. 
MINISTÉRIO DA CUlTURA. Plano Nacional de Cultura - Anexo ao Projeto de Lei $\mathbf{N}^{\mathbf{0}}$ 6.835. Brasília, 2009.

OLIVEN, Ruben George. A relação Estado e cultura no Brasil: cortes ou continuidades? In: MICELI, Sergio (org.) Estado e Cultura no Brasil. São Paulo: Difel, 1984.

ORTIZ, Renato. A moderna tradição brasileira. São Paulo: Brasiliense, 1988. . Cultura Brasileira e Identidade Nacional. São Paulo: Brasiliense, 2006.

RIDENTI, Marcelo. Em busca do povo brasileiro - artistas da revolução, do CPC à era da TV. Record: Rio de Janeiro; São Paulo, 2000. Artistas e Intelectuais no Brasil pós 1960. Revista Tempo Social. São Paulo: USP, Departamento de Sociologia, vol. 17, n 1, 2005.

ROCHA, Maria Eduarda da Mota. Guel Arraes: Leitura social de uma biografia. In: FECHINE, Y. et al. Guel Arraes - um inventor no audiovisual brasileiro. Recife: Cepe, 2008.

A Nova Retórica do Capital: A Publicidade Brasileira em Tempos Neoliberais. São Paulo: Edusp, 2010.

RUBIM, Antonio Albino Canelas (org.). Políticas culturais no governo Lula. Salvador, EDUFBA, 2010.

SILVA, Frederico A. Barbosa da \& MIDLEJ, Suylan (orgs.) Políticas públicas culturais: a voz dos gestores. Brasília, Ipea, 2011.

TURINO, Célio. Ponto de cultura: o Brasil de baixo para cima. São Paulo, Anita Garibaldi, 2010.

WEFFORT, Francisco. Cultura é um bom negócio. Ministério da Cultura (MinC), Brasília, 1991.

WILLIAMS, Raymond. Culture is ordinary. In: Resources of hope culture, democracy and socialism. Londres: Verso, 1958.

Terra, 1992.

Cultura: Sociologia da Comunicação e da Arte. Rio de Janeiro: Paz e

WISNIK, José Miguel. O nacional e o popular na cultura brasileira - música. São Paulo, Brasiliense, 1982. 
YUDICE, George. A conveniência da cultura - usos da cultura na era global. Belo Horizonte: Editora da UFMG, 2004.

Recebido em 25/06/2019.

Aprovado em 04/11/2019. 